\title{
Teaching by Recycling; Transferring the Individually-Obtained Knowledge by a Single Student to All Other Students
}

\author{
Sama'a Al Hashimi ${ }^{1}$ \\ ${ }^{1}$ University of Bahrain, Sakheer, Kingdom of Bahrain \\ Correspondence: Sama'a Al Hashimi, University of Bahrain, B.O Box: 32038, Sakheer, Kingdom of Bahrain. \\ E-mail: dr.samaa.alhashimi@gmail.com
}

Received: May 26, $2019 \quad$ Accepted: June 29, $2019 \quad$ Online Published: July 18, 2019
doi:10.5539/jel.v8n4p214
URL: https://doi.org/10.5539/jel.v8n4p214

\begin{abstract}
In computer-based courses such as multimedia and digital design courses, being fully conversant with a computer application is almost unachievable within a single academic semester. Therefore, it is common for students to seek additional help and information from their lecturers either during office hours or through emails. It is also common for students to acquire skills from online tutorials, books, friends, or private tutors, which may cause the student to possess more advanced computer skills than others, including their lecturers. The knowledge that is individually acquired by the student from the teacher or from other sources is usually limited to that single learner. Therefore, this action research proposes a new teaching method; Teaching by Recycling (TBR) whereby the effort of teaching a single student is recycled into the practice of teaching all students together. The main aim is to transfer the individually-obtained knowledge from the teacher or from other sources to other students. This research explores the implications of TBR and investigates its effectiveness in augmenting the pedagogical efficiency and scope of teaching students individually through expanding this scope to include teaching all students collectively.
\end{abstract}

Keywords: teaching, recycling, multimedia, design, art, graphic design

\section{Introduction}

This action research is undertaken to investigate the effectiveness of one of my teaching strategies, which I refer to as Teaching by Recycling (TBR); collecting and reprocessing material taught to an individual student by reusing it for the purpose of teaching other students. This allows for the time and effort exerted by a single student in acquiring knowledge or by a single teacher in delivering information within the context of a private tutorial to be returned back to the educational mainstream either in the form of a public tutorial (by the teacher) or a peer-tutorial (by the student). In the former case, the teacher may reuse the student's questions, design problems, enquiry material, and projects as teaching material in what could be considered a peer problem-solving approach. In the latter case, the teacher may encourage the student to teach that enquiry material or any individually-learned material to other students.

TBR can have various applications. It can be implemented in the form of recycling what is taught during office hours into what is taught during class hours. It can also be in the form of recycling students' questions and email enquiries as problem-solving material and subsequently as exam questions. Another application involves recycling students' projects in the form of class exercises. Former students' evaluations of the teacher and experiences of the course can also be recycled when teaching new students. Moreover, the knowledge instilled in former students can be recycled by inviting these students as tutors for a new class. Thus, TBR attempts to minimise educational waste by converting former or even current students' knowledge, enquiries, projects, and feedback into usable teaching material that might otherwise become wasted, academically.

TBR may be used as a complementary teaching approach to Learning by Teaching, which refers to shifting the roles between the student and the teacher whereby the student teaches other students. The French Professor Jean Pol Martin is accredited for the development of Learning by Teaching (LDL) (Duymedjian, 2004, pp. 181-194) during the early eighties. Since then, there has been a plethora of literature on LDL (e.g., Annis, 1982; Bargh \& Schul, 1984; Aslan, 2015; Duran, 2016).

LDL shares some characteristics with Constructivism and so does TBR. Constructivism encourages "students to 
construct their own knowledge" (Dagar, 2016, p. 2). TBR also encourages individual knowledge-construction in order to subsequently convert it into collective knowledge-construction.

Another shared characteristic is active learning, whereby students are encouraged to have an active role in learning and are engaged and involved in the learning process (Bonwell \& Eison, 1991). TBR involves active learning because it promotes student-generated exercises, student-led lectures, student-independent learning from external resources, peer feedback, and peer teaching.

A further common characteristic is that the teacher and the students are "equally involved in learning from each other" (Holt \& Willard-Holt, 2000, cited in nghipandulwa, 2011, p. 2). Due to these shared characteristics, TBR could possibly add a new perspective to constructivist learning theory and practice. The aim and objective of this action research is to address the following questions:

1) How effective is TBR in transferring the individually-obtained knowledge by a single student to all other students?

2) What are the limitations and implications of TBR?

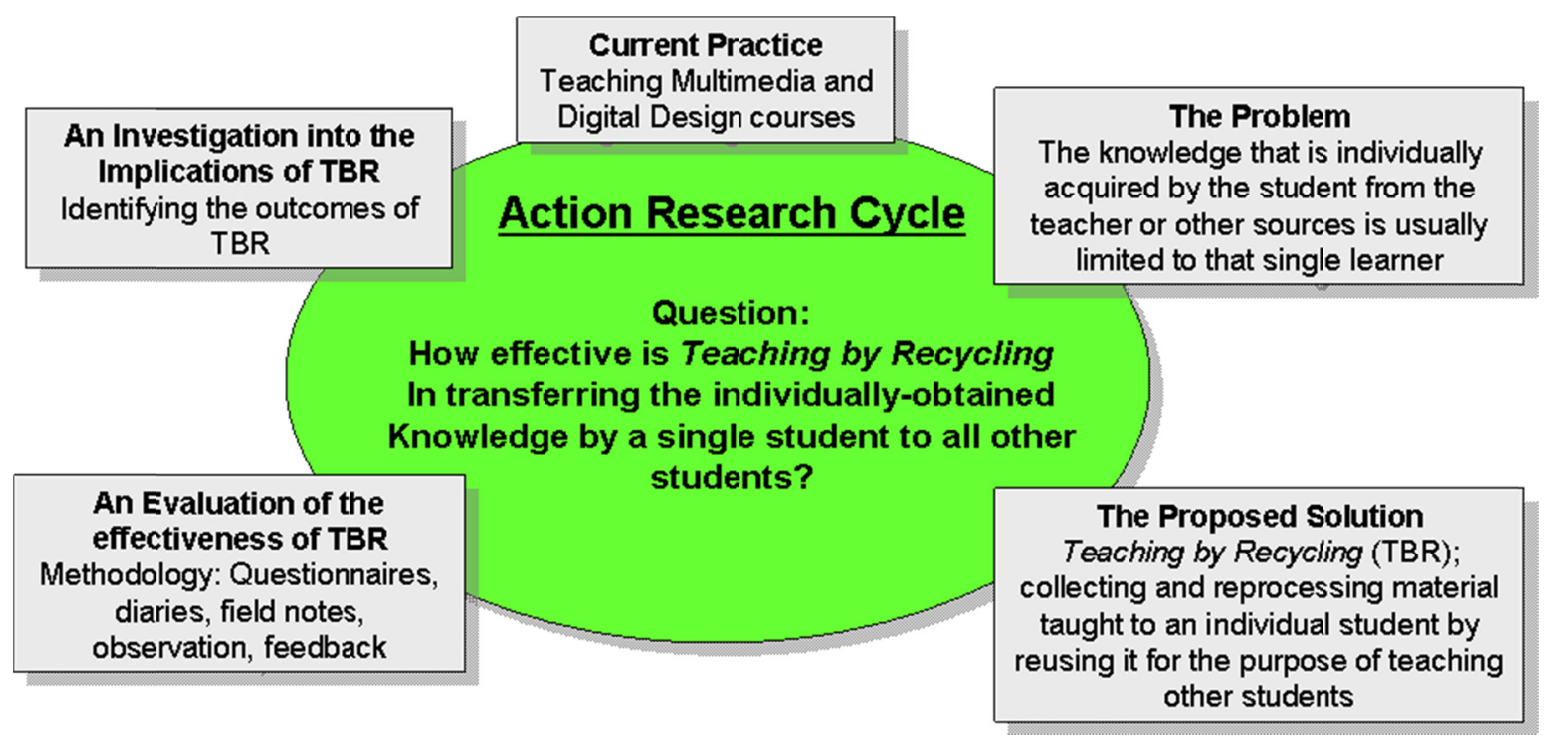

Figure 1. A diagram illustrating the action research cycle

It is important to emphasize that in order to find answers to these enquiries, I principally adopted an explorative approach. However, in order to reflect upon this approach and undertake an evaluation of its outcomes, parts of the work are underpinned by methodological enquiry. The framework of this research is based on the cycle illustrated in Figure 1.

This first section presents a brief introduction to the action research and discusses the underlying motives. It notes the research literature which has been done in relation to TBR. It presents the objectives that are to be achieved and the research problems and questions that are to be examined, and outlines the theoretical framework of the research as a whole. The second section presents the literature review, and the third section proposes my solution to the research problem through the implementation of various applications of TBR in my academic practice. It also presents the results of my evaluation of the effectiveness of TBR as a pedagogical approach in teaching multimedia and digital design courses. The fourth section discusses and reveals some aspects that have appeared as implications of - or possible limitations to-TBR. In the concluding section, the objectives, arguments and findings are briefly restated and their implications are assessed in an attempt to prompt the development of other forms of TBR of which the ultimate objective is to enhance learning outcomes through allowing all students to benefit from what each student learns within and beyond the classroom.

\section{Literature Review}

This section discusses developments and various approaches to recycling, repurposing, or reusing educational resources, skills, and knowledge. Over the last decade researchers and educators have explored the concept of 
reusing resources and repurposing materials in education. The expectation is that this approach would potentially result in more effective and efficient education. For instance, some studies (Pegler, 2011) related to this topic, have focused on the repurposing of online digital resources within higher education and have investigated reusable learning objects (RLO) and open educational resources (OER). These studies explored the reuse of educational material for teaching and learning through defining "reusable chunks of documents that can be retrieved, adapted and assembled in a coherent way for a given educational purpose" (Vercoustre, 2005, p. 3).

Vercoustre (2005) also encourages reusing teaching and learning materials indicating that "anyone who has had to create learning materials from scratch knows just how labour intensive and time consuming the process can be, even with the existence of a detailed course descriptions and lesson plans."

Wills and Pegler (2016) also encourage reusing learning materials and resources and suggests that not enough attention has been given to the use of reusable learning resources. They state that "there is limited incentive for academics to select a resource for reuse, let alone repurpose it for reuse" and suggest that there is a need for both a broad and deep understanding of how to better facilitate sharing and reusing of learning materials, resources and activities especially through the networking potential of Web 2.0 tools such as Twitter, LinkedIn, Google+, which facilitate the establishment of sharing communities;

It is assumed that uptake and adoption of educational technology in teaching will be faster if teachers reuse educational resources developed by other teachers rather than "reinventing the wheel". University teachers use educational materials, digital or otherwise, by breaking the materials into their constituent parts, reusing those parts that are relevant to their subject, context and perspective, and reassembling those parts from the original package along with parts from other packages to form a new set of educational materials. It is assumed that systems that mirror teachers' natural instinct to reuse chunks in their own preferred order for their own context will assist uptake and adoption of educational technology. The vision for reuse is expressed in the Larnaca Declaration (Dalziel et al. in this Special Collection) and yet there is a lack of research on how this theory works in practice (Wills \& Pegler, 2016, p. 1).

Within the topic of reusing, repurposing or recycling educational material, various strategies have emerged and have been implemented such as "Learning Objects, Open Educational Resources (OER), Reusable Learning Objects (RLO), Reusable c Objects, Generative Learning Objects (GLO) and Learning Designs" (Wills \& Pegler, 2016, p. 1)

These strategies have emerged with the emergence of new technologies and open educational resources, which allowed students to find various resources and platforms for self-learning. This has led the teacher nowadays to be considered more of a facilitator of the learning process than "someone who is at the heart of the educational process" (Biesta, 2013), and teachers are encouraging self-directed learning and other learning approaches including strategies and approaches that promote the transfer of knowledge gained by students from various resources. Bransford et al. (1999, p. 39) stated, "Educators hope that students will transfer learning from one problem to another within a course, from one year in school to another, between school and home, and from school to the workplace". Many other researchers explored various strategies to transfer knowledge and skills, but mainly focused on transferring these skills from the university to the workplace. On the other hand, transferring skills from a student to the rest of the students either by the students themselves or by their instructors has been limited to approaches such as peer-tutoring or peer-assisted learning. There should be more research into how the transferable skills gained through peer-tutoring and through other forms of attainment can effectively be transferred, recycled, repurposed, and reused to teach other students. Therefore, the rest of this paper evaluates the effectiveness of recycling students' projects, students' feedback, and students' experiences and skills and repurposing them into usable teaching material for other students.

\section{Method}

This section aims to describe and evaluate the various applications of TBR that I have implemented during my academic practice. These applications include recycling office hours, projects, feedback forms, and former students. In order to investigate the effectiveness of the aforementioned applications among multimedia and digital image design students at the University of Bahrain, I carried out a study to investigate my students' attitudes towards TBR and to examine its implications and limitations. Two anonymous questionnaires were used to elicit data for this study because the questions required anonymity for students to be able to answer candidly. The subjects were third-year multimedia students who attended my Digital Image Design course during the current academic year. They were orally informed about the study, and were told that participation was optional.

In order to study the effectiveness of recycling virtual and actual office hours, I handed out the first questionnaire 
(questionnaire A) to thirteen students towards the end of the semester. The questions were all open-ended, which required reflection. Thus, the students were asked to complete it at home. Some of the questions were derived from a questionnaire prepared by Maddalena (2002, p. 10) to assess the use of students as teaching assistants in a mixed-ability classroom.

In order to study the effectiveness of recycling students' projects, students' feedback, and students, I handed out another questionnaire (questionnaire B) to sixteen students at the beginning of the semester (during the third lecture). The questionnaire consisted of open-ended and closed questions. Because the questions required instant recall and feedback on the TBR practices implemented in that lecture, students were asked to answer them immediately after experiencing those TBR practices (which are explained in the following paragraphs).

Before handing out questionnaire B, I circulated feedback forms containing comments about me and the course from nine former students. The students were then given two exercises that were based on projects of former students who enquired about the techniques that I was explaining on that day. In order to avoid ethical issues, I asked my former students to sign a consent form before using their projects.

After completing the exercise, I invited two excellent former students as visiting lecturers to discuss their own experiences and to explain the course requirements. They also taught students several Photoshop techniques. Afterwards, I left the classroom for ten minutes to allow a free dialogue between current and former students. Finally, questionnaire B was handed out and students were given twenty minutes to complete it. The findings will be discussed throughout the rest of this section under the relevant application of TBR.

\section{Results: An Evaluation of the Implementation of Teaching by Recycling}

\subsection{Teaching by Recycling Actual and Virtual Office Hours}

This section aims to describe and evaluate the implementation of recycling actual and virtual office hours. Office hours are important opportunities to give personal attention to students (Guerrero \& Rod, 2013). To reflect the significance of office hours, Nadler and Nadler (2000, p. 9) stated that "Education does not stop at the classroom doors and neither should our scholarly exploration of communication in this environment". However, there is very little research on holding efficient office hours. One way to make office hours more productive is to recycle them. Teachers might sometimes minimise the time spent with each individual student in order to serve as many students as possible. Recycling office hours drastically shifts this attitude; teachers can spend as much time as required by a student because that time and effort will be recycled for the benefit of others. Accordingly, "Education does not stop at the classroom door" (ibid) and neither does it stop at the office door; whatever is taught in the office can be recycled back into the classroom.

During office hours students may ask questions and share ideas more openly. Nevertheless, some students might be "intimidated" by visiting the teacher during office hours (Brain, 1998) or feel reluctant because they think that they are "disturbing or imposing upon their professors" (The McGraw Center, 2008).

Asking students to share with the rest of the class what they have individually learned during office hours may encourage them to visit the teacher and may also encourage the teacher to invest more time with each individual student. By convincing students that they will collectively benefit from office visits, they may feel "a greater sense of self worth from doing something meaningful for someone else" (Beasley, 1997, pp. 26-27). Moreover, students are sometimes able to explain ideas in simpler ways than teachers. Chin and Anderson suggest that when students explain an idea, they tackle it from a "common lack of understanding" (2005, p. 16), whereas the teacher already understands the idea and may approach it differently. One of my students explained this as follows: "The teacher conveys information in a clear manner without any doubt, but when a student teaches other students, that student will have the same level of understanding as other students and will therefore be able to convey information in a more simplified manner". According to another student, peer-tutors "are within a similar age range and therefore students will not hesitate to ask them questions that they might feel embarrassed to ask the teacher".

The notion that teaching is an effective way to learn is widely "supported in the research literature" (Leelawong, 2005, p. 307) (eg., Stollhans, 2016; Aslan, 2015). According to Biggs (2003, p. 80), most people learn 50\% of "what they see and hear", and $95 \%$ of "what they teach someone else". The effectiveness of involving the student actively in the learning and teaching process was also emphasized by Tyler who stated that "Learning takes place through the active behaviour of the student: it is what he does that he learns, not what the teacher does" (Tyler, 1949, cited in Biggs, 2003, p. 25). One of my students believed that recycling office hours through peer-tutoring is useful "because the student teaches and learns". Another student found it useful because s/he "felt that the task is easy and doable when a student like him/her is able to do it". A third student found it useful 
because "teaching and repeating what has been learned makes it stay in the mind".

The pie chart in Figure 2 reflects my students' views on the usefulness of peer-tutoring in general. On the other hand, the pie chart in Figure 3 reflects my students' views on the usefulness of recycling actual and virtual office hours. Ten out of thirteen students found peer-tutoring useful. Eleven out of thirteen students found recycling actual and virtual office hours useful. In view of that, the method of teaching by recycling what has been taught in the office complements the method of "Learning by Teaching" in the class. When the student teaches by recycling, that student simultaneously learns by teaching.

Do you find it useful when a student teaches you and other students in the class?

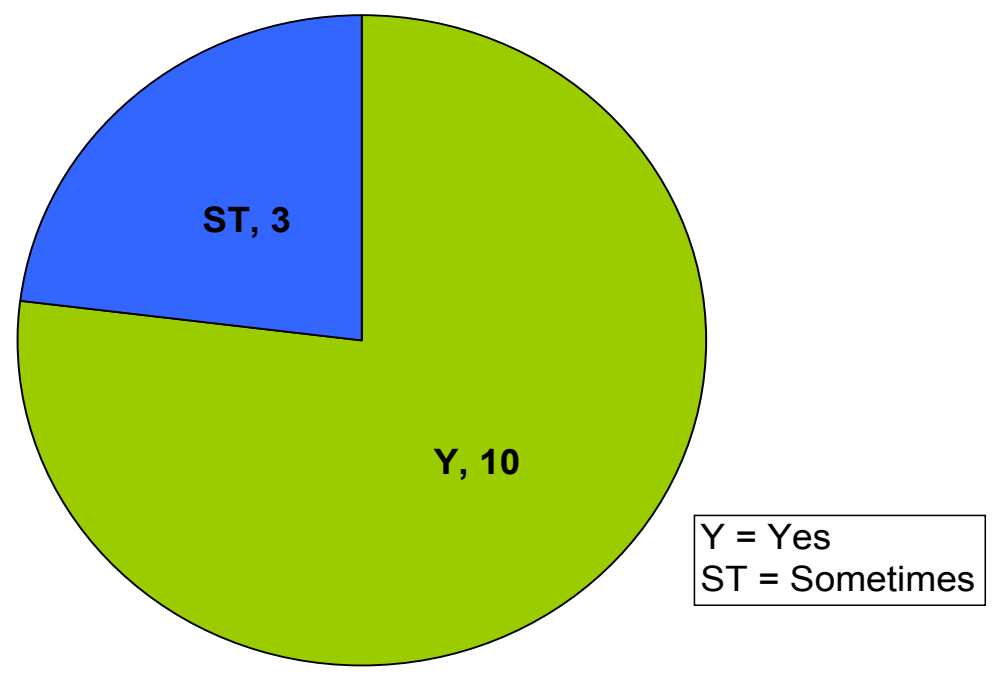

Figure 2. Feedback from thirteen students on the usefulness of peer-tutoring

Out-of-class enquiries can be recycled through addressing those enquiries with the entire class. When a student raises a question or problem during office hours, it is likely that many other students have the same question (Brain, 1998). Hence, the teacher must address such questions or problems again in class for the benefit of other students (ibid). The teacher may also ask the enquiring student to repeat the question and its answer in class, upon his/her consent. One of my students believes that recycling out-of-class tutorials and enquiries is useful because "there isn't enough time to explain a specific thing or correct the same mistake for each student. So, if a student teaches what he has learned to other students, time is saved and the benefit is widespread". Another student also thinks "it saves the time of students who have the same query but cannot meet the teacher during office hours". 


\section{Do you find it useful when students teach you what I taught them either during office hours or by email?}

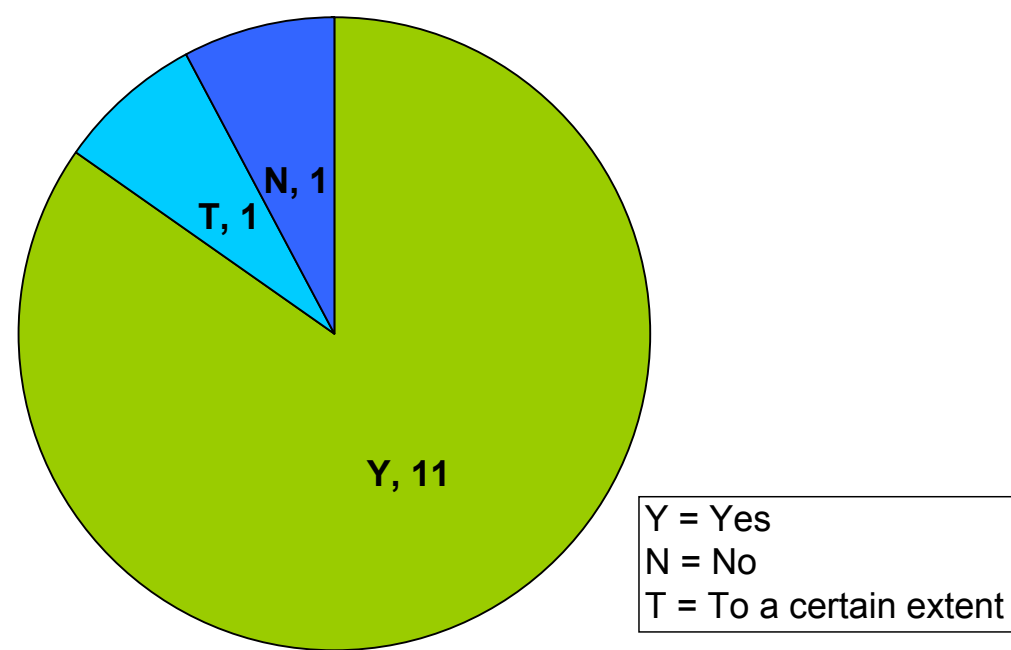

Figure 3. Feedback from thirteen students on the usefulness of recycling what has been taught to a single student

Socrates believed that "thinking is driven by questions" (Elder, 1998, cited in Bartlett, 2015). I therefore recycle students' questions in what could be considered a questions-driven teaching approach; whereby a major part of what I teach is driven by the questions that are raised during office hours. Students seem to be more interested and involved when I teach them what they want to know rather than what I want them to know. This is also supported by Erickson's statement that "students learn what they care about" (Erickson, 1984, cited in Mukherjee, 2005, p. 486).

The teacher's comments on a student's project is another aspect of office hours that can be recycled. The teacher can make a list of comments given to a student during office hours, and then repeat them-or ask the student to repeat them-in class. Recycling students' mistakes and suggested improvement allows them to "learn from each other's mistakes and hence avoid these mistakes in the next project", as one of the surveyed students indicated. It also enables students to self-assess their projects. Some of them even mention their mistakes as soon as they start presenting their projects. It also allows them to peer-assess other students' projects, based on my assessment of previous projects. Thus, the teacher's feedback is recycled either in the form of self-feedback or peer-feedback. This enables them to develop a critical eye for their own work as well as the work of others.

Recently, an increasing number of teachers are conducting virtual office hours to "supplement regular office hours" and to cater to "students with different learning styles" (Hooper et al., 2006) (eg., Lowenthal, 2017). Virtual office hours give students the opportunity to ask urgent questions if they are unable to attend - or wait until-actual office hours. Although face-to-face office hours are necessary, more teachers are communicating with their students online, mainly through e-mail (Waldeck et al., 2001; Jones \& Johnson-Yale, 2005, cited in Roper \& Kindred, 2005) (Rahman, 2013). In addition to e-mail, other means of online communication with students include chat rooms, social networking sites (Rahman, Junayed, \& Masoom, 2015) and digital apps (such as Remind, Facebook and Instagram), VOIP (such as Skype and Google Talk), Learning Management Systems (such as Schoology, Blackboard, and Moodle), document sharing services (such as YouSendIt, DropSend, and LeapFILE).

A major drawback of online communication is the loss of the visual modality, which limits the teacher's ability to assess comprehension through facial expressions and body language (Hooper et al., 2006). Despite this concern, there are numerous benefits from virtual office hours (Baker \& Edwards, 2011). I personally make use of systematically archiving students' emails and attachments in order to recycle questions, problems and past projects. The next section discusses how these project-related email enquiries can be recycled in the form of exercises in future classes. 


\subsection{Teaching by Recycling Students' Projects}

The objective of this section is to describe and evaluate the implementation of recycling students' projects. In order to teach my students how to design in Photoshop, I have been using a tutorial book along with a CD that contains step-by-step exercises. However, some students felt that "the book is boring". For this reason, I decided to recycle projects from previous as well as current students in the form of exercises. This allowed me to build course content from students' projects. My aim was to foster students' interest by using teaching material that they feel is generated by them rather than imposed on them. Giving them exercises from student-generated content seemed to increase their interest and motivation because these exercises are more relevant to them. Some researchers believe that students develop a sense of engagement in learning activities that they consider relevant to them (Driscoll, 2000, cited in Mukherjee, 2005; Brozo, 2005). Wardrop noticed that his students prefer studying other students' projects versus "professional" research that he presents (Wardrop, 2000). This is in line with my findings as depicted in Figure 4.

Six out of sixteen students preferred learning from students' projects. Eight students preferred learning from both students' projects and the book (Figure 6). This indicates that most students found that recycling students' projects (either with or without the use of the book) is useful. The next section goes beyond recycling students' projects. It aims to demonstrate how former students' experiences and course feedback can be recycled as well.

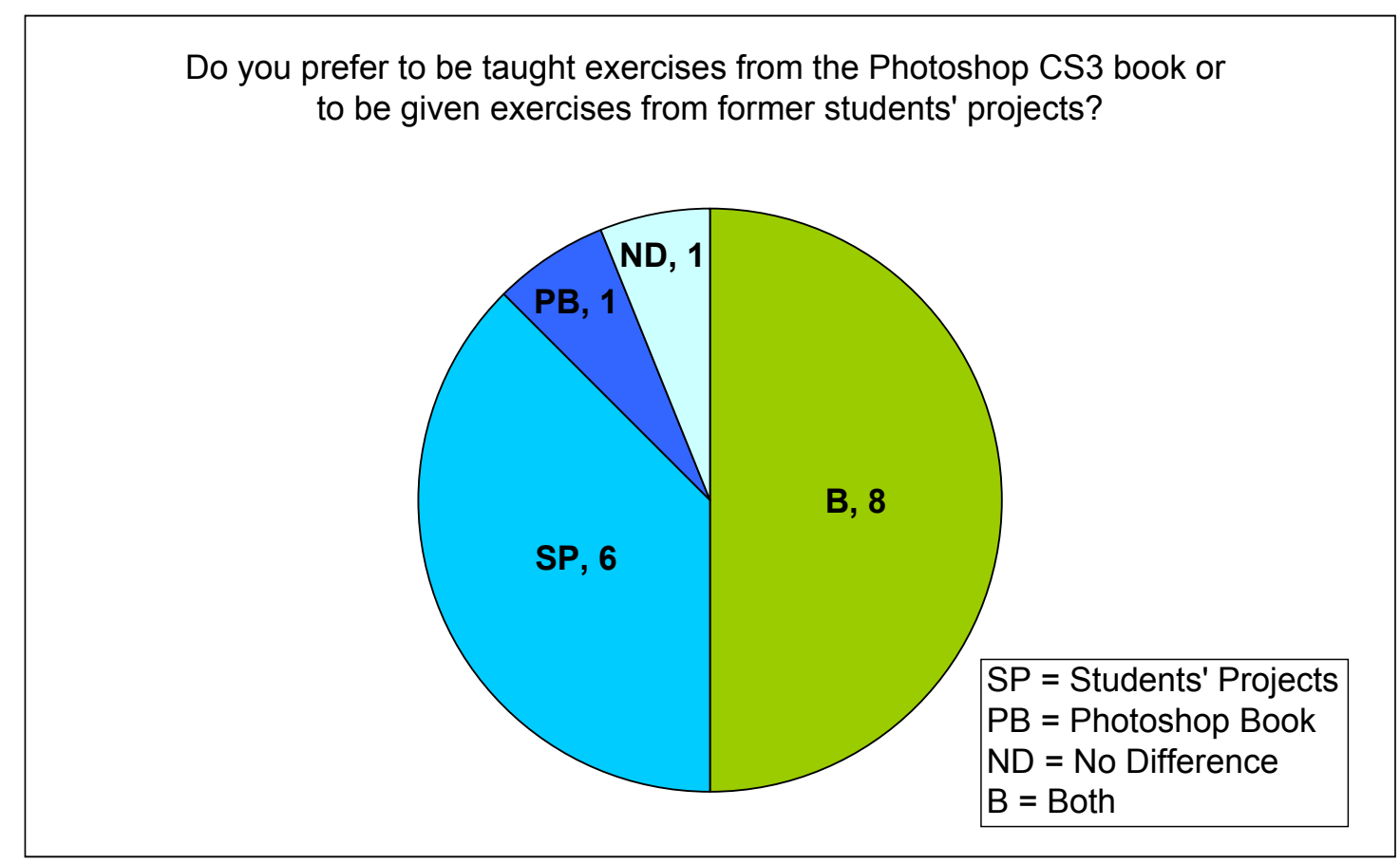

Figure 4. The preferences of sixteen students in connection to recycling students' projects as exercises

\subsection{Teaching by Recycling Students' Feedback}

Since I started teaching, I noticed that students post questions about me in online forums in an effort to get feedback from my former students. This led me to copy a student's detailed inquiry about my teaching and convert it into a questionnaire. The questionnaire was filled out by my current students and then recycled as a feedback form that can now be read by new students in future classes.

During the third lecture in the semester for my Digital Image Design class, I circulated nine forms containing former students' feedback about me and the course. However, only seven out of sixteen students found the form useful (Figure 5). 


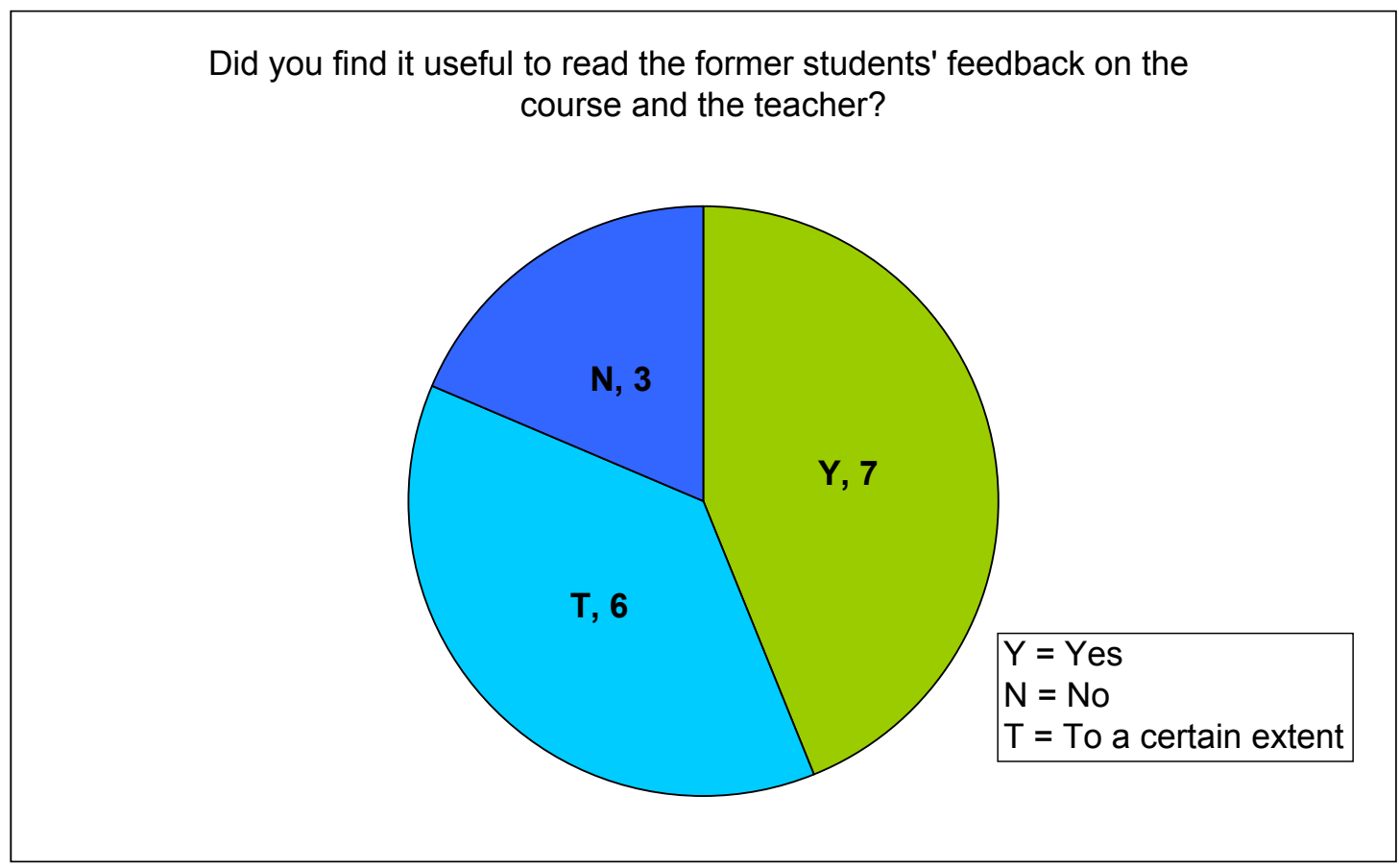

Figure 5. Students' opinions on recycling former students' feedback

This unexpected result might be due to timing. The forms were recycled during the third lecture in the semester rather than the first. By then, students had adequate time to know me or to ask others about me and the course, and so they did not necessarily need to read feedback forms by other students. In view of that, recycling students' feedback might be more useful to prospective students rather than to students who are already enrolled in my class. It is important to provide prospective students with access to these feedback forms (e.g., online). Another approach could be to recycle feedback in an oral manner by recycling former students themselves. Having current students listen to former students share their course experiences, turned out to be more useful than just reading written feedback. The following section provides evidence for this (Figure 6).

\subsection{Teaching by Recycling Students}

Students are a valuable and exploitable teaching resource (Beasley, 1997, p. 21; Maddalena, 2002, p. 1; Pardo \& María Fernanda Téllez, 2009). The knowledge and experience that they acquire from teachers or from other resources, may be recycled during current or future classes. This allows exceptional current students to actively serve as peer-tutors rather than remain passive and "overlooked" (Maddalena, 2002, p. 1). It also allows outstanding former students to serve as peer-models and peer-tutors, rather than remain unacknowledged and their experiences academically unexploited. According to Alderman (1999, p. 77): "The use of peer models is especially recommended for enhancement of self-efficacy among low-achieving students who are more doubtful about attaining the level of competence demonstrated by the teacher". This is also evident in the following statement by one of the surveyed students: "The peer-tutor can be a role model to students, so that they can become like him/her one day".

Recently, I have been inviting outstanding former students to explain course requirements to new students. I then leave the classroom for ten minutes and allow a free dialogue between former and new students. By doing so, former students get to recycle their learning experiences. Getting face-to-face feedback from former students turned out to be more useful than written feedback. Only seven out of sixteen students found recycled written feedback useful (Figure 5). However, fifteen students found face-to-face feedback useful (Figure 6).

The same former students also gave a detailed Photoshop tutorial during the same lecture (Figure 8 illustrates a sample of presented work). Fourteen out of sixteen current students found recycling former students useful (Figure 7). Eleven out of sixteen current students preferred to have both former students as well as myself as tutors.

I have also been inviting excellent former students to attend current students' presentations in order to comment on their work based on what they previously learned in the same course. Thus, the knowledge and experience of 
former students is recycled for the benefit of current students. Even current students can be recycled. When current students acquire knowledge from external resources, they can recycle it by tutoring their peers. Asking students to explain how they designed their projects during presentations serves two purposes: to share skills with teachers and other students, and to prove that the work has not been done by someone else.

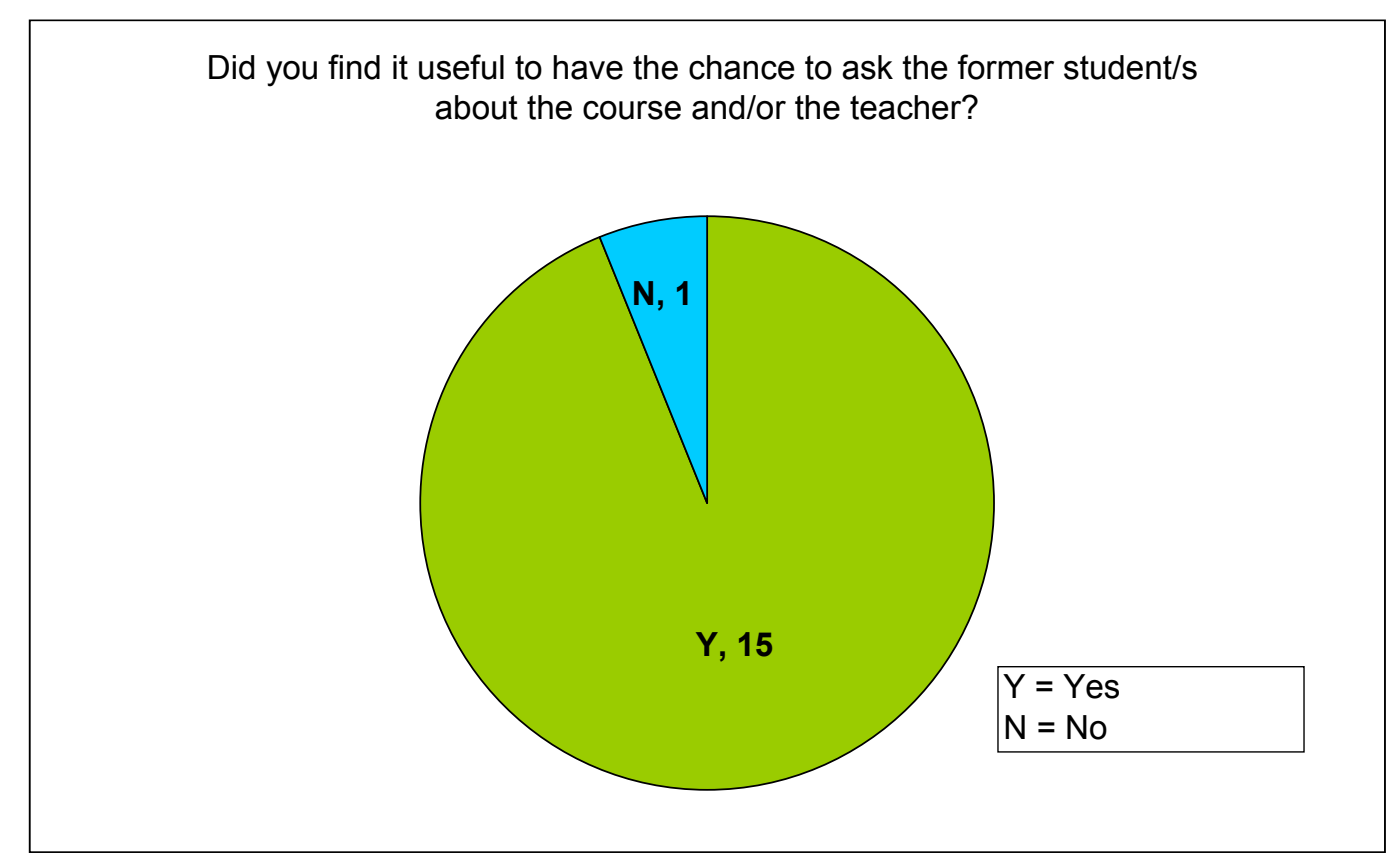

Figure 6. The opinions of sixteen students in connection to face-to-face feedback from former students

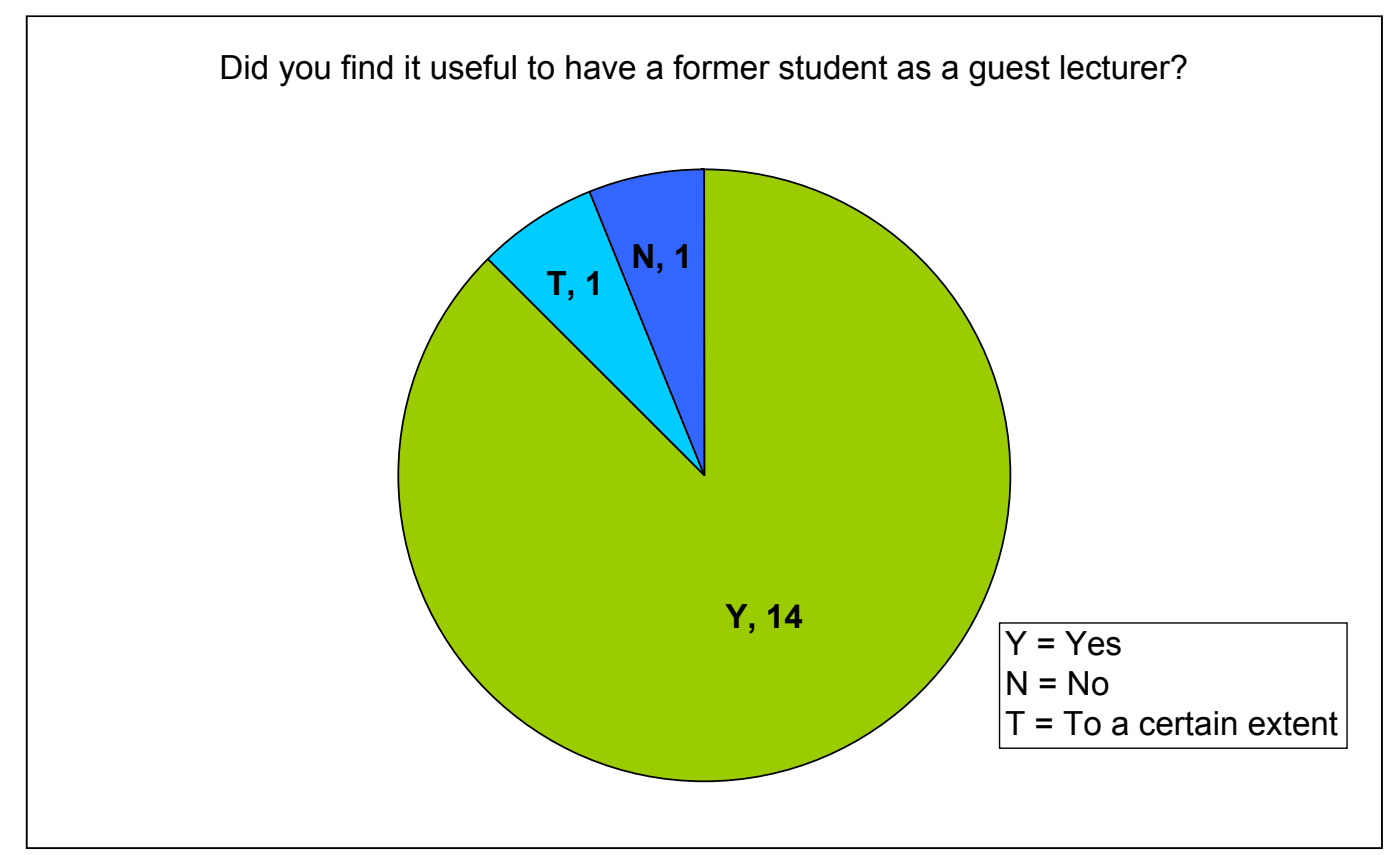

Figure 7. The opinions of sixteen students in connection to recycling Former students as guest lecturers 


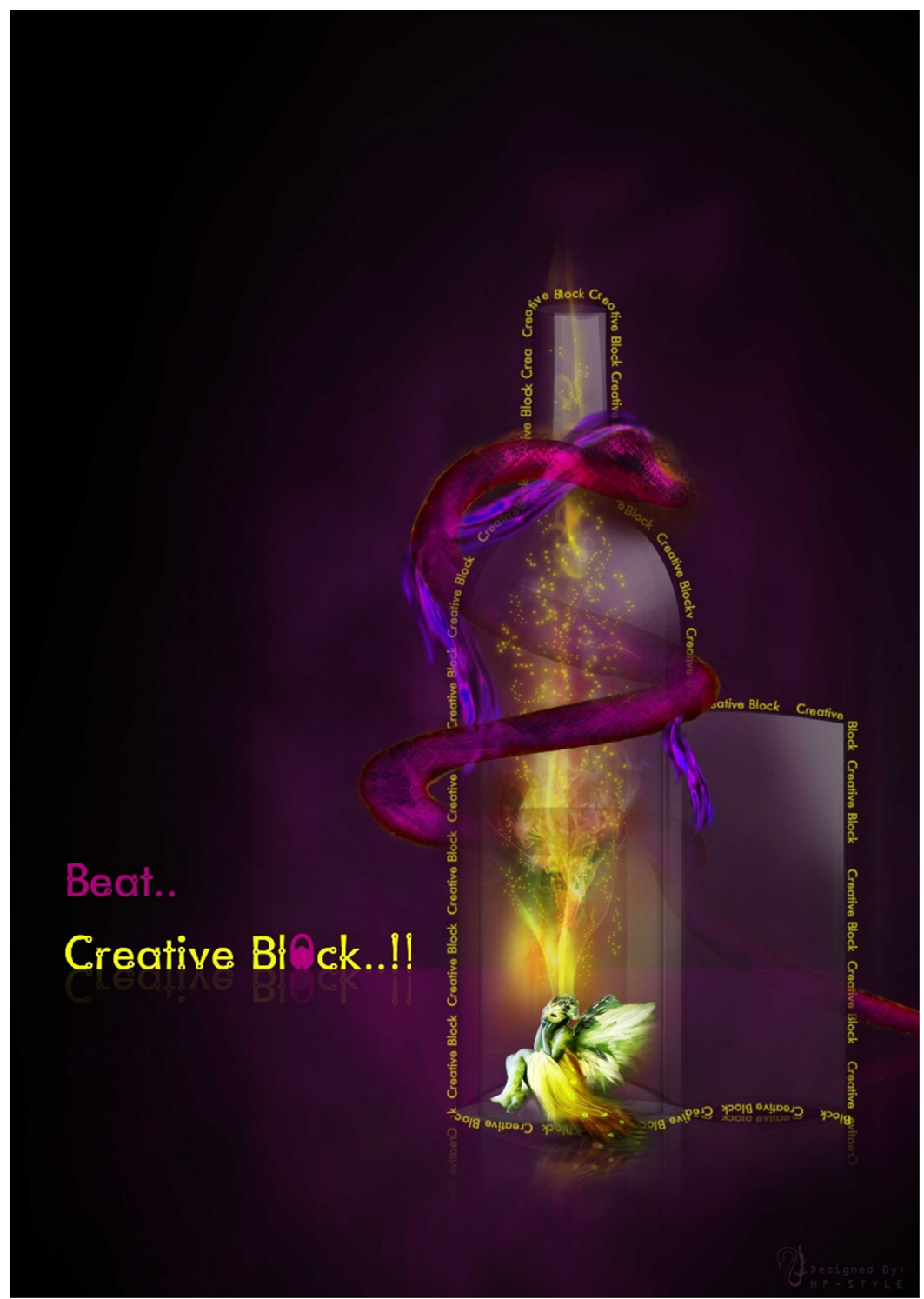

Figure 8. A project that was recycled by a former student when invited as a guest-lecturer. This project was used to teach current students how to form various brushes in Photoshop in order to create some surreal effects

\section{Discussion}

It must be noted that this study was conducted under tight limitations. It was completed in a short time-frame of eight months, and thus data was collected through one academic semester only. The number of students in my classes during this year was low, and thus the sample size was not large enough to ensure statistical significance. In fact, these parameters qualify the evaluation as a pilot study. As a result, I am not in a position to firmly promote the rigour of the findings based on the collected empirical data. The purpose of this study was to evaluate my personal implementation of TBR, and to explore its implications. To evaluate a new educational intervention such as TBR, a comprehensive research programme is required - not just a primitive consideration of some limitations and implications (covered in the following section). The aim of the next section is to reveal some of the implications of - or possible limitations to-TBR. It analyses the findings and their implications in an attempt to lay the foundation for future research on this topic.

\section{Conclusions, Implications, and Limitations}

I embarked on this action research aiming to investigate the following questions:

1) How effective is TBR in transferring the individually-obtained knowledge by a single student to all other students? 
2) What are the limitations and implications of TBR?

I argued that TBR may be an effective teaching strategy to transfer the individually-obtained- knowledge to the rest of the class. I now have evidence to support this argument, but also a much greater insight into the implications and limitations of TBR.

One of the limitations of teaching by recycling office hours is that it might not be practical for teachers who do not wish to spend more time online as it may disrupt their social lives. Another limitation relates to the reluctance of male students to visit me during office hours. There are studies that suggest that the student's gender affects the frequency of out-of-class communication (OCC) (Felts et al., 2006). This seems applicable in the Bahraini culture, especially for religious reasons. I was once in my office with four female students when a male student came to ask for help. When I asked him to come in, he said that he will come later because he is not comfortable sitting in an office full of females.

There are also some technical limitations to recycling virtual office hours; some students do not have an internet connection at home, and some files are too big to be sent via e-mail or uploaded through free file-sharing services. However, the biggest challenge to virtual office hours is holding brain-storming sessions. This is particularly challenging since some ideas "cannot be easily communicated by email", as one of the surveyed students indicated.

The benefits of recycling office hours still outweigh all these limitations. Recycling feedback given to students on their projects during office hours "helps the rest of the students avoid making mistakes in their projects", according to one of the students. Another student stated that recycling office hours "saves the time of students who have the same query but cannot meet the teacher in the office". Moreover, another student also stated that "It instils a sense of cooperation and collaboration between students, and strengthens students' relationships". Yet another student pointed that it also makes students feel that the information recycled by a peer-tutor is "easy because a student like them is able to teach it to them".

One of the chief concerns related to teaching by recycling students as tutors is that some students might feel that the peer-tutor "lack(s) credibility and knowledge" (Glynn et al., 2006, p. 16), and might not teach them "as conscientiously as the teacher would", according to one of the surveyed students. Therefore, I agree with Glynn et al. in that "students are not qualified to be teachers" and "they can give incorrect or misleading information" (2006, p. 16). Hence, peer-tutoring must take place under close supervision by the teacher; the role of the peer-tutor "should be one of facilitation rather than of teaching" (ibid). Despite this concern, pairing current and former students "provides psychological support and aids professional and personal development" (ibid, p. 2). When paired together, these students share skills and cooperate to achieve their goals in what is referred to as "promotive interaction" (ibid, p. 15).

Recycled former students may serve as role models or even mentors for current students, guiding them towards fulfilling course requirements, and providing advice, support, and encouragement. Following the tutorial that was given by the former students, two current students asked me if they could teach their peers some Photoshop techniques in future lectures. This approach increases students' motivation and encourages them to be active learners who autonomously seek knowledge from external sources in order to share it or even show it off to their peers in an attempt to "win their peers' as well as their teacher's admiration", as stated by one of the surveyed students.

Recycling students can also have other benefits. According to Brems, during peer-tutoring students become more alert and their attention and interest are augmented through the change in approach (Brems, 2004), which is exactly what I witnessed when I recycled students as tutors.

It seems reasonable to conclude that some of the applications of TBR are highly accepted by students and that this strategy is effective in optimizing teaching and learning endeavours within and outside the realm of the classroom. TBR also seems to be effective in unlocking the potential of each student through motivating them to gain a sense of responsibility for aiding their own as well as their peers' learning. Nonetheless, I recommend the development of further studies on this approach before more definitive conclusions may be reached.

\section{References}

Alderman, M. (1999). Motivation for Achievement: Possibilities for Teaching and Learning. Mahwah, NJ: Lawrence Erlbaum.

Annis, L. F. (1982). The cognitive benefits of peer tutoring. Paper presented at the meeting of the American Educational Research Association, New York. 
Aslan, S. (2015). Is Learning by Teaching Effective in Gaining 21st Century Skills? The Views of Pre-Service Science Teachers. Educational Sciences: Theory and Practice, 15(6), 1441-1457. https://doi.org/10.12738/estp.2016.1.0019

Baker, C. T., \& Edwards, J. T. (2011). A holistic approach for establishing social presence in online courses \& programs. The International HETL Review, 1. Retrieved from http://hetl.org/2011/08/17/social-presence-in-online-courses/

Bargh, J. A., \& Schul, Y. (1984) On the cognitive benefits of teaching. Journal of Education Psychology, 72, 593-604. https://doi.org/10.1037//0022-0663.72.5.593

Bartlett, J. (2016). Outstanding differentiation for learning in the classroom. Abingdon: Routledge. https://doi.org/10.4324/9781315733654

Beasley, C. (1997). Students as teachers: The benefits of peer tutoring. In R. Pospisil \& L. Willcoxson (Eds.), Learning Through Teaching. The 6th Annual Teaching Learning Forum (February 21-30). Retrieved September 15, 2018, from http://ctl.curtin.edu.au/events/conferences/tlf/tlf1997/beasley.html

Biesta, G. J. (2013). Giving teaching back to education: Responding to the disappearance of the teacher. Phenomenology \& Practice, 6(2), 35-49. https://doi.org/10.29173/pandpr19860

Biggs, J. (2003). Teaching for Quality Learning at University (2nd ed.). The Society for research into Higher Education and Open University Press.

Bonwell, C. C., \& Eison, J. A. (1991). Active learning: Creating excitement in the classroom. ASHE-ERIC Higher Education Report No. 1, The George Washington University, School of Education and Human Development.

Brain, M. (2018). Emphasis on Teaching. BYG Publishing. Retrieved April 15, 2018, from http://www.bygpub.com/eot/eot8.htm

Bransford, J. D., Brown, A. L., \& Cocking, R. R. (Eds.). (1999). How people learn: Brain, mind, experience, and school. Retrieved March 29, 2019, from http://www.nap.edu/books/0309070368/html/

Brems, B. (2018). Education World (Planning for a Substitute was Never this Easy). Retrieved May 2, 2018, from http://www.education-world.com/a_curr/voice/voice110.shtml

Brozo, W. G. (2005). Connecting with students who are disinterested and inexperienced. Thinking Classroom, $6(3), 42-43$.

Chin, P., \& Anderson, A. (2005). Using e-learning to promote peer learning and assessment (pp. 15-19). Proceedings of The Science Learning and Teaching Conference, University of Warwick, Centre for Bioscience, the Higher Education Academy.

Dagar, V., \& Yadav, A. (2016). Constructivism: A Paradigm for Teaching and Learning. Arts Social Science Journal, 7(200). https://doi.org/10.4172/2151-6200.1000200

Duran, D. (2016). Learning-by-teaching. Evidence and implications as a pedagogical mechanism. Innovations in Education and Teaching International, 54(5), 476-484. https://doi.org/10.1080/14703297.2016.1156011

Duymedjian, R. (2004). Can "Learning by Teaching" Contribute to E-Learning? Educational Innovation in Economics and Business, 9, 181-194. https://doi.org/10.1007/1-4020-3171-8_10

Felts, O., Trowbridge, M., \& Hample, D. (2006) Engaging or Not Engaging in Out-of-Class Communication: Students' Episodic Perceptions, Impressions of Instructors, and Locus of Control. Paper presented to the annual meeting of the International Communication Association, Dresden International Congress Centre, Dresden, Germany.

Glynn, L. G. et al. (2006). Helping each other to learn - a process evaluation of peer assisted learning. BMC Med Educ, 6(1), 18. https://doi.org/10.1186/1472-6920-6-18

Guerrero, M., \& Rod, A. B. (2013). Engaging in office hours: A study of student-faculty interaction and academic performance. Journal of Political Science Education, 9(4), 403-416. https://doi.org/10.1080/15512169.2013.835554

Hooper, J., Pollanen, M., \& Teismann, H. (2006). Effective Online Office Hours in the Mathematical Sciences. MERLOT Journal of Online Learning and Teaching, 2(3), 187-194.

Leelawong, K. (2019). Vanderbilt University (Using the Learning-by-Teaching Paradigm to Design Learning Environments).

Retrieved

April

25,

2019,

from 
http://portal.acm.org/citation.cfm?id=1123943\&coll=GUIDE\&dl=GUIDE

Lowenthal, P. R., Dunlap, J. C., \& Snelson, C. (2017). Live synchronous web meetings in asynchronous online courses: Reconceptualizing virtual office hours. Online Learning, 21(4), 177-194. https://doi.org/10.24059/olj.v21i4.1285

Maddalena, S. (2019). TESL (Using High Level Students as Teaching Assistants in a Mixed Ability Classroom). Retrieved May 15, 2019, from http://www.tesl-ej.org/ej21/cf1.html

Mukherjee, A. (2005). Use of class exercise to maximize student interest in an introductory MIS course. Issues in Information Science and Information Technology, 2, 481-494. https://doi.org/10.28945/845

Nadler, M. K., \& Nadler, L. B. (2000). Out-of-class communications between faculty and students: A faculty perspective. Communication Studies, 51(2), 176-188. https://doi.org/10.1080/10510970009388517

Nghipandulwa, L. (2018). University of Namibia (Secondary school teachers' perceptions of the importance of practical work in biology in Oshana educational region). Retrieved April 15, 2018, from http://www.isis.unam.na/theses/nghipandulwa2011.pdf

Pardo, A. N., \& María Fernanda Téllez, T. (2009). ELT Materials: The Key to Fostering Effective Teaching and Learning Settings Materiales para la enseñanza del inglés: la clave para promover ambientes efectivos de enseñanza y aprendizaje. Profile Issues in Teachers' Professional Development, 11, 171-186.

Pegler, C. (2011). Reuse and Repurposing of Online Digital Learning Resources within UK Higher Education: 2003-2010. PhD thesis The Open University.

Rahman, A., Junayed, M., \& Masoom, M. (2015). Students' Perception of the Effects of Online Social Networking: An Empirical Assessment. International Letters of Social and Humanistic Sciences, 65, 152161. https://doi.org/10.18052/www.scipress.com/ILSHS.65.152

Rahman, S. B. (2013). Students' Use of Email and Facebook: A Comparative Perspective (Dissertation). Retrieved September 21, 2018, from http://urn.kb.se/resolve?urn=urn:nbn:se:uu:diva-217809

Roper, S. L., \& Kindred, J. (2018). First Monday (Reflections on virtual office hours). Retrieved June 16, 2018, from http://firstmonday.org/htbin/cgiwrap/bin/ojs/index.php/fm/article/view/1292/121

Stollhans, S. (2016). Learning by teaching: developing transferable skills. In E. Corradini, K. Borthwick \& A. Gallagher-Brett (Eds.), Employability for languages: a handbook (pp. 161-164). https://doi.org/10.14705/rpnet.2016.cbg2016.478

The McGraw Center. (2008). Helping Students Get More Out of Office Hours. Retrieved May 25, 2019, from https://mcgraw.princeton.edu/node/1221

Vercoustre, A. M., \& Mclean, A. (2005). Reusing Educational Material for Teaching and Learning: Current Approaches and Directions. Association for the Advancement in Computing in Education (AACE). International Journal on E-Learning, 4(1), 57-68.

Wardrop, R. (2019). MAA Notes (Small Student Projects in an Introductory Statistics Course). Retrieved April 10, 2019, from http://www.stat.wisc.edu/ wardrop/papers/tmoore.pdf

Wills, S., \& Pegler, C. (2016). A deeper understanding of reuse: learning designs, activities, resources and their contexts. Journal of Interactive Media in Education, 1. https://doi.org/10.5334/jime.405

\section{Copyrights}

Copyright for this article is retained by the author, with first publication rights granted to the journal.

This is an open-access article distributed under the terms and conditions of the Creative Commons Attribution license (http://creativecommons.org/licenses/by/4.0/). 